\title{
Elemene inhibits the migration and invasion of 4T1 murine breast cancer cells via heparanase
}

\author{
YI ZHANG $^{1}$, XU SUN $^{1}$, NAN NAN $^{1}$, KE-XIN CAO $^{1}$, CONG MA $^{1}$, GUO-WANG YANG ${ }^{1}$, \\ MING-WEI YU ${ }^{1}$, LIN YANG ${ }^{1}$, JIN-PING LI ${ }^{1,2}$, XIAO-MIN WANG ${ }^{1}$ and GAN-LIN ZHANG ${ }^{1}$ \\ ${ }^{1}$ Department of Oncology, Beijing Hospital of Traditional Chinese Medicine, Capital Medical University, \\ Beijing 100010, P.R. China; ${ }^{2}$ Department of Medical Biochemistry and Microbiology, \\ Biomedical Center, Box 582, Uppsala University, S-751 23 Uppsala, Sweden
}

Received April 16, 2016; Accepted March 24, 2017

DOI: $10.3892 / \mathrm{mmr} .2017 .6638$

\begin{abstract}
Elemene (ELE), a natural plant drug extracted from Curcumae Rhizoma, has been widely used for cancer treatment in China for more than 20 years. Although it is reported to be a broad-spectrum anticancer drug, the mechanism underlying the action of ELE in the treatment of breast cancer remains to be fully elucidated. Heparanase, a mammalian endo-D-glucuronidase, is involved in degradation of the extracellular matrix (ECM), and thus promotes tumor progression and metastasis. The downregulation of heparanase can effectively reduce tumor malignant behaviors. In the present study, the inhibitory effects of ELE were evaluated in breast cancer cells using a Cell Counting kit 8 assay. The migratory and invasive capabilities of cancer cells were investigated using a wound healing assay, real-time cell analysis and a Transwell assay. In addition, western blot analysis was used to assess alterations in the expression levels of key proteins. The present results confirmed the antiproliferative and antimetastatic effects of ELE, using low-molecular weight heparin (LMWH) as a positive control. In addition, ELE was demonstrated to downregulate the expression of heparanase, and decrease the phosphorylation of extracellular signal-regulated kinase and AKT. These findings suggested that ELE may be a promising agent targeting heparanase in the treatment of breast cancer.
\end{abstract}

\section{Introduction}

Breast cancer is a common malignant tumor in women, with $\sim 1,700,000$ cases and 521,900 cases of mortality in 2012

Correspondence to: Dr Xiao-Min Wang or Dr Gan-Lin Zhang, Department of Oncology, Beijing Hospital of Traditional Chinese Medicine, Capital Medical University, 23 Back Road of Art Gallery, Dong Cheng, Beijing 100010, P.R. China

E-mail: wangxiaomin_bhtcm@126.com

E-mail: kalinezhang@163.com

Key words: elemene, invasion, migration, heparanase, extracellular regulated kinase, AKT worldwide (1). The incidence of breast cancer is progressively increasing, particularly in the urban regions of China. Official data predicted a continuing increase in mortality rates in the ensuing 5 years (2). According to current understanding, tumor metastasis remains the dominant cause for cancer-associated mortality (3). Therefore, it is necessary to identify or develop drugs with antimetastatic ability for breast cancer therapy.

Tumor metastasis is a multi-step process, in which the key step is the degradation of extracellular matrix (ECM) by certain enzymes, including matrix metalloproteinases (MMPs) and heparanase $(4,5)$. Heparanase is a mammalian endo-D-glucuronidase, which cleaves heparan sulfate (HS) involved in the formation of ECM. The expression level of this enzyme correlates with the metastatic potential of tumor cells $(6,7)$. It has been demonstrated that the overexpression of heparanase results in intensive angiogenesis, lymph node metastasis, advanced clinical stage and short overall survival rates in lung, breast, colon and ovarian cancer (8-11). These poor outcomes can be partly ascribed to the degradation of ECM by heparanase. The overexpressed heparanase impairs the structural integrity of ECM. Subsequently, the degradation of HS chains promotes the release of growth factors, including fibroblast growth factor (FGF), vascular endothelial growth factor (VEGF) and platelet-derived growth factor, from ECM, which activate the downstream signaling pathways, facilitating the proliferation and metastasis of cancer cells $(12,13)$. The nonenzymatic function of heparanase also directly stimulates Akt-dependent endothelial cell invasion and migration activities (14). Therefore, heparanase is a target of interest for the prevention of cancer metastasis.

Elemene (ELE) is a natural plant drug extracted from Curcuma wenyujin. A previous study demonstrated the extensive spectrum of antitumor effects of ELE, involving lung cancer, breast cancer, gastric cancer and brain tumors (15). The effects of ELE are not only on the inhibition of cancer cells, but also on the regulation of the tumor microenvironment, including inhibition of epithelial-mesenchymal transition (EMT) (16), decreased angiogenesis (17) and inhibition of ECM degradation by MMPs (18). As a key enzyme involved in degrading the ECM in the tumor microenvironment, whether the expression of heparanase can be inhibited by ELE remains to be elucidated and requires further investigation. 
Low-molecular weight heparin (LMWH), an analog of the natural substrate of heparanase, is considered a potent inhibitor of heparanase $(7,19,20)$, thus, serving as a positive control. In the present study, the antiproliferative and antimetastatic effects of ELE were confirmed. In addition, it was found that ELE downregulated the expression of heparanase and potentially decreased the phosphorylation of extracellular signal-regulated kinase (ERK) and AKT in 4T1 murine breast cancer cells.

\section{Materials and methods}

Chemicals and reagents. $\beta$-elemene (purity, 98\%; molecular formula, C15H24; molecular weight, 204.35) was obtained from Dalian Jingang Pharmaceuticals, Ltd. (Liaoning, China). The LMWH was purchased from Aventis Intercontinental (Paris, France).

Primary antibodies against heparanase (cat no. ab85543) and VEGF (cat no. ab46154) were purchased from Abcam (Cambridge, UK). The primary antibodies against fibroblast growth factor (FGF)-2 (cat. no. sc-79) and $\beta$-actin (cat no. sc-47778) were purchased from Santa Cruz Biotechnology, Inc. (Houston, TX, USA). The primary antibodies against ERK (cat no. \#9102), phosphorylated (p)-ERK (cat no. \#4377), AKT (cat no. \#9272) and p-AKT (cat no. \#4058) were purchased from Cell Signaling Technology, Inc. (Danvers, MA, USA). The secondary antibodies, including Dylight 800-conjugated goat anti-mouse (cat no. 072-07-18-06) and Dylight 680-conjugated goat anti-rabbit IgG (cat no. 072-06-15-06) were purchased from KPL, Inc. (Gaithersburg, MD, USA).

Cell culture. The 4T1 murine breast cancer cells (Cell Bank of the Chinese Academy of Sciences, Shanghai, China) were cultured in RPMI-1640 (Gibco; Thermo Fisher Scientific, Inc., Waltham, MA, USA). The MCF-7, MDA-MB-231 and MDA-MB-435S human breast cancer cell lines were purchased from the Cell Center of Medical Research Institute, Chinese Academy of Medical Sciences. The MCF-7 cells were cultured in DMEM (Gibco; Thermo Fisher Scientific, Inc.), whereas the MA-MB-231 and MDA-MB-435S cells were cultured in Leibovitz's L15 (Hyclone; GE Healthcare Life Sciences, Logan, UT, USA). The media was supplemented with $10 \%$ fetal bovine serum (FBS; Gibco; Thermo Fisher Scientific, Inc.) and $1 \%$ penicillin-streptomycin (Hyclone; GE Healthcare Life Sciences). The cells were trypsinized with $0.125 \%$ trypsin (Gibco) and were seeded onto microplates for the subsequent experiments. All cell lines were cultured at $37^{\circ} \mathrm{C}$ in a humidified incubator (Sanyo, Osaka, Japan) supplied with $5 \%$ carbon dioxide $\left(\mathrm{CO}_{2}\right)$.

Cell Counting kit-8 (CCK-8) cytotoxicity assay. The cytotoxicity of ELE was measured using a CCK- 8 assay. The cells were inoculated in a 96-well plate (Corning, Steuben County, NY, USA) at $3 \times 10^{3}$ cells/well, incubated overnight at $37^{\circ} \mathrm{C}$ with $5 \% \mathrm{CO}_{2}$, and were exposed to different concentrations of ELE (10-160 $\mu \mathrm{g} / \mathrm{ml})$ or LMWH (50-800 IU/ml as a positive control) for 24 or $48 \mathrm{~h}$. Following ELE and LMWH exposure, $15 \mu$ l CCK-8 (KeyGEN Biotech Co., Ltd., Nanjing, China) was added to each of the wells. The cells were incubated for another $4 \mathrm{~h}$ at $37^{\circ} \mathrm{C}$ with $5 \% \mathrm{CO}_{2}$. The absorbance values were measured at $450 \mathrm{~nm}$ using a microplate reader (Thermo Fisher Scientific, Inc.). The optical density (OD) was determined to calculate the rate of inhibition, which is expressed as follows: Inhibition rate $=[1-(\mathrm{OD}$ of experimental sample-OD of blank group)/(OD of control group-OD of blank group)]x $100 \%$.

Electric cell-substrate impedance sensing (ECIS) wound healing assay. The ECIS assay was used to measure the healing ability of the 4T1 cells (21). A $400 \mu 1$ suspension of 4T1 with $8 \times 10^{4}$ cells were seeded in $8 \mathrm{~W} 10 \mathrm{E}+$ ECIS arrays (Applied Biophysics, Inc., Troy, NY, USA) in each well. Following inoculation of the cells, the procedure of attachment and spreading was exhibited by impedance measurements. Lethal electroporation (current, 6,500 $\mu \mathrm{A}$; frequency, 100,000 Hz; time, $60 \mathrm{sec})$ was performed when the cells were fully confluent $(\sim 16 \mathrm{~h})$. The dead cells were washed away and fresh medium containing ELE $(25 \mu \mathrm{g} / \mathrm{ml})$ and LMWH $(200 \mathrm{IU} / \mathrm{ml})$ was added. The wound healing was assessed by continuous impedance measurements for $20 \mathrm{~h}$. The experiment was performed in a humidified $5 \% \mathrm{CO}_{2}$ incubator at $37^{\circ} \mathrm{C}$ and was repeated three times.

Real-time cell analysis (RTCA) migration assay. RTCA was used for determining cell migration on an xCELLigence DP device (Roche Diagnostics, Mannheim, Germany) as described in the manufacturer's protocol and previous study (22). The migration assay was performed on a CIM-plate16 (Roche Diagnostics), comprising a two-chamber device separated by an aporous membrane. Either cell attachment or cell migration directly through pores to the lower surface of the membrane, where electrodes exist, can be recorded. A 10\% FBS solution was added to the bottom chamber, and the top chamber was assembled using the CIM-plate assembly tool. The 4T1 cells treated with ELE $(25 \mu \mathrm{g} / \mathrm{ml})$ and LMWH $(200 \mathrm{IU} / \mathrm{ml})$ were collected and counted, following which $6 \times 10^{4}$ cells in $100 \mu 1$ serum-free medium were seeded into the top chamber of the CIM-plate16. The xCELLigence device recorded the migratory information from $4 \mathrm{~T} 1$ cells for $24 \mathrm{~h}$. The cell indices represented the migration capacity of the $4 \mathrm{~T} 1$ cells treated with drugs.

Transwell migration and invasion assay. The 4T1 cells were exposed to ELE at $25 \mu \mathrm{g} / \mathrm{ml}$ and LMWH at $200 \mathrm{IU} / \mathrm{ml}$ for $36 \mathrm{~h}$. The cells were collected in a serum-free medium at $5 \times 10^{5}$ cells $/ \mathrm{ml}$. A $100 \mu \mathrm{l}$ suspension was added to the top chambers, coated with Matrigel (BD Biosciences, San Diego, CA, USA) with or without growth factors. In the lower chamber, $600 \mu \mathrm{l}$ of RPMI-1640 medium containing $10 \%$ FBS was added to the 24-well plate. The cells were cultured at $37^{\circ} \mathrm{C}$ with $5 \% \mathrm{CO}_{2}$ for $24 \mathrm{~h}$. After $24 \mathrm{~h}$, the cells were fixed with methanol for $10 \mathrm{~min}$ at $-20^{\circ} \mathrm{C}$. Cells on the apical side of the top chamber were removed using a cotton swab. Those cells, which migrated or invaded to the lower side of the membrane were stained with Hoechst 33342 (Sigma-Aldrich; Merck KGaA, Darmstadt, Germany) for $15 \mathrm{~min}$ at $25^{\circ} \mathrm{C}$. The cells were counted under a fluorescence microscope (magnification, x200; Leica Microsystems GmbH, Heidelberg, Germany). Data were collected from three independent experiments. 



Figure 1. ELE inhibits breast cancer cell proliferation in a dose-dependent manner. The inhibition rate of cells was calculated by comparing them with the untreated group. The proliferation of (A) MCF-7, (B) MDA-MB-231, (C) MDA-MB-435S and (D) 4T1 cells were inhibited by ELE in a dose-dependent manner in vitro. (E) LMWH inhibited 4T1 proliferation, but with no dose-dependent effect. ELE, elemene; LMWH, low-molecular weight heparin.

Western blot analysis. 4T1 cells were cultured in $100 \mathrm{~mm}$ dishes and exposed to ELE at $25 \mu \mathrm{g} / \mathrm{ml}$ and LMWH at $200 \mathrm{IU} / \mathrm{ml}$ for $36 \mathrm{~h}$. Subsequently, the cells were harvested and lysed with radioimmunoprecipitation assay lysis buffer (Beyotime Institute of Biotechnology, Jiangsu, China) containing protease inhibitor cocktail set III (Merck KGaA). The protein content was measured using a bicinchoninic acid protein assay kit (Pierce; Thermo Fisher Scientific, Inc.). Following denaturation by boiling, equal amounts of extracted protein samples $(30 \mu \mathrm{g})$ were separated by $4-10 \%$ SDS-PAGE and transferred onto a polyvinylidene difluoride membrane. The membrane was blocked with $5 \%$ skimmed milk for $2 \mathrm{~h}$ at room temperature and probed with the following primary antibodies at $4^{\circ} \mathrm{C}$ overnight: Anti-heparanase rabbit-polyclonal antibody (1:500), anti-FGF-2 rabbit-polyclonal antibody (1:500), anti-VEGF rabbit-polyclonal antibody $(1: 1,000)$, anti-ERK/p-ERK rabbit-polyclonal antibodies $(1: 1,000)$, anti-AKT/p-AKT rabbit-polyclonal antibodies $(1: 1,000)$ and anti- $\beta$-actin $(1: 1,000)$, which was followed by incubation with secondary antibodies $(1: 10,000)$ for $1 \mathrm{~h}$ at room temperature. The protein of interest was detected using Odyssey infrared imaging system (LI-COR Biosciences, Lincoln, NE, USA). Blots were semi-quantified by densitometric analysis 
A
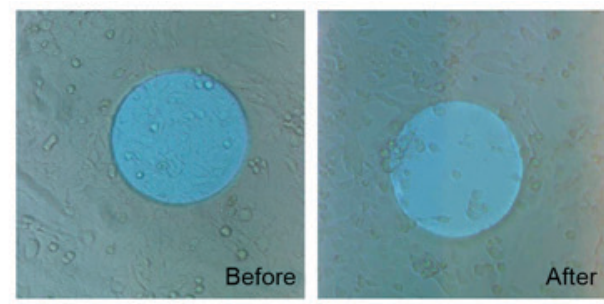

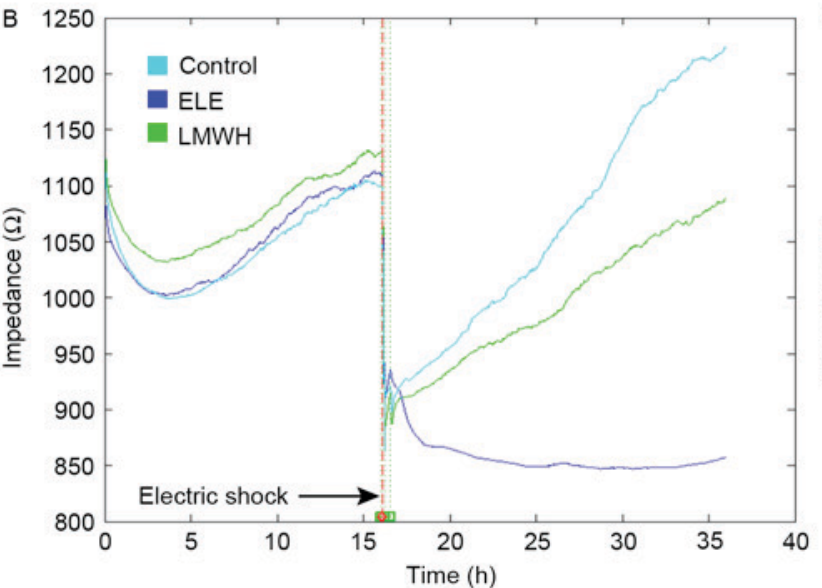

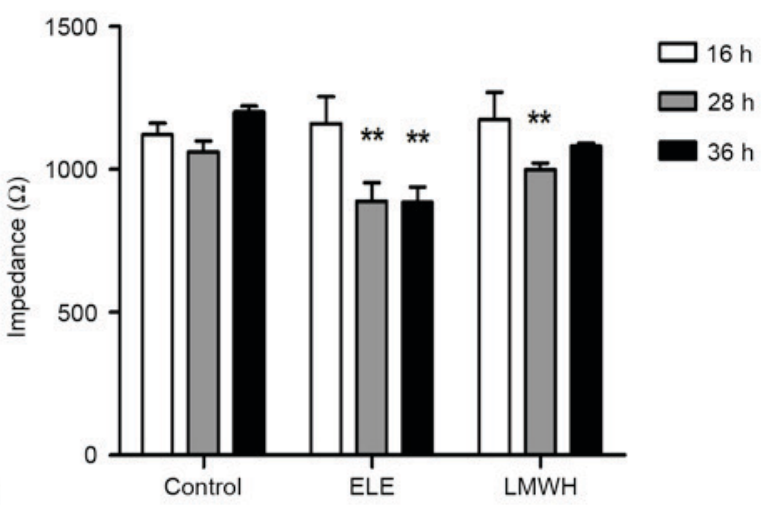

Figure 2. ELE inhibits the wound healing ability of 4T1 cells. (A) ECIS-induced lethal electroporation of cells $16 \mathrm{~h}$ following cell seeding (before). Following electric shock, 4T1 cells in contact with the $250 \mathrm{~mm}$ diameter electrode were compromised and washed away (after). Photomicrographs were captured under x40 magnification. (B) Impedance time course during wound healing from a representative experiment of 4T1 cells treated with vehicle (RPMI-1640 medium), ELE at $25 \mu \mathrm{g} / \mathrm{ml}$ and LMWH at $200 \mathrm{IU} / \mathrm{ml}$. The whole procedure was recorded using ECIS for $36 \mathrm{~h}$. (C) Data on wound healing was further analyzed with a before-after comparison. Differences were significant in the ELE ( 28 and $36 \mathrm{~h})$ and LMWH groups ( $28 \mathrm{~h})$, compared with the level in the same group at $16 \mathrm{~h}$ $\left({ }^{* *} \mathrm{P}<0.01\right)$. ELE, elemene; ECIS, electric cell-substrate impedance sensing; LMWH, low-molecular weight heparin.

using the Odyssey software version 3.0 (LI-COR Biosciences) and protein expression was normalized to $\beta$-actin. The experiments were repeated three times.

Statistical analysis. Data are expressed as the mean \pm standard deviation. The statistical significance of the differences between the control and drug treatment groups was assessed using Student's t-test for pair-wise comparisons, or a one-way analysis of variance followed by a post hoc Dunnett's test for multiple comparisons. Statistical analysis was performed using the GraphPad Prism software version 5.0 (GraphPad Software Inc., San Diego, CA, USA). $\mathrm{P}<0.05$ was considered to indicate a statistically significant difference.

\section{Results}

Inhibitory effect of ELE on cell proliferation in breast cancer cells. To examine the effect of ELE on cell viability in different breast cancer cells, the cells were treated with ELE $(10-160 \mu \mathrm{g} / \mathrm{ml})$ for 24 or $48 \mathrm{~h}$, and the inhibitory rate of the cells was determined using a CCK-8 assay. The half-inhibitory concentrations of ELE were 25.31 and $21.31 \mu \mathrm{g} / \mathrm{ml}$ in the 4T1 cells at 24 and $48 \mathrm{~h}$ respectively. The half-inhibitory concentrations values of ELE for MCF-7 (51.26 and $38.88 \mu \mathrm{g} / \mathrm{ml}$ for 24 and $48 \mathrm{~h}$ ), MDA-MB-231 (49.9 and $41.92 \mu \mathrm{g} / \mathrm{ml}$ for 24 and $48 \mathrm{~h}$ ) and MDA-MB-435s cells (35.5 and $37.07 \mu \mathrm{g} / \mathrm{ml}$ for 24 and $48 \mathrm{~h}$ ) were higher, compared with those of the 4T1 cells. The results showed that ELE (10-80 $\mu \mathrm{g} / \mathrm{ml})$ resulted in a dose-dependent inhibition of 4T1, MCF-7, MDA-MB-231 and MDA-MB-435s cells (Fig. 1A-D). In the 4T1 cells,
LMWH did not exhibit an inhibitory effect, compared with ELE (Fig. 1E).

ELE reduces the wound healing ability of $4 T 1$ cells. To assess the wound healing ability of the ELE-treated 4T1 cells, impedance was determined using ECIS following electric shock wounding. Following wounding of the cells electrically, the impedance recorded using ECIS returned to the basal level, as the cells attached on the electrode were compromised (Fig. 2A). Subsequently, the healthy neighboring cells migrated inwards and replaced the dead cells. With drug treatment, the speed and ability of cell migration were altered to a certain extent. The impedance of the control group healed to its primary level ( $16 \mathrm{~h}$, fully confluent) at $28 \mathrm{~h}$, whereas the LMWH group required a longer duration to heal ( $\sim 36 \mathrm{~h})$. Additionally, the ELE group failed to repair over the $36 \mathrm{~h}$ (Fig. 2B), and the differences in impedance between pre- and post-wounding were significant (Fig. 2C). These results suggested that the wound healing ability of the ELE-treated cells was limited.

ELE decreases cell migration and invasion. The present study further investigated whether ELE can inhibit the migratory and invasive ability of 4T1 cells using impedance-based detection of migration and a Transwell assay. The cells in the control group began to migrate earlier, compared with those in the ELE and LMWH groups. The migration ability of the control group also remained higher until the end of the experiment. The migration abilities of the cells in the ELE and LMWH groups were lower. The differences in cell indices between the drug-treated 

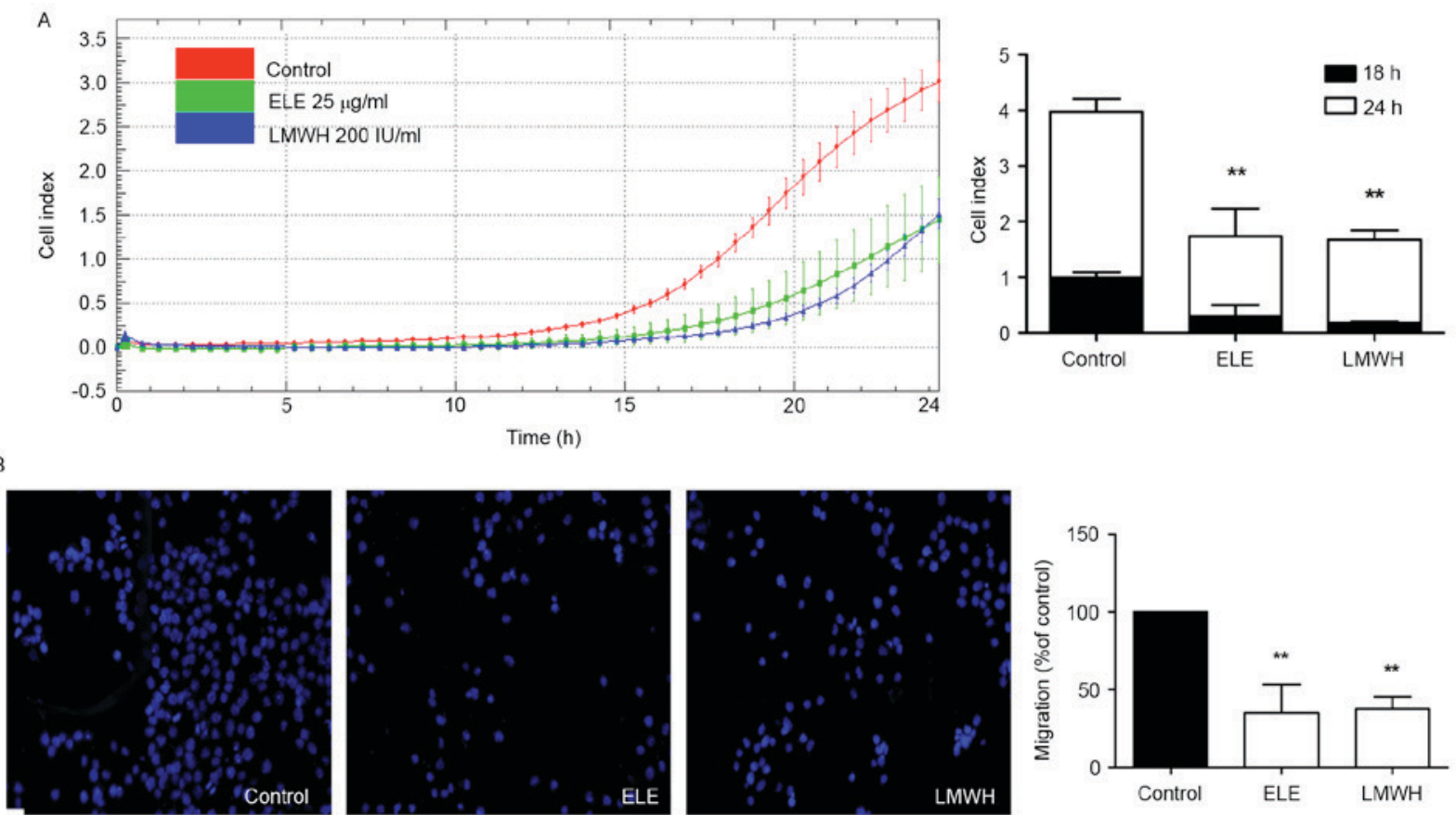

Migration
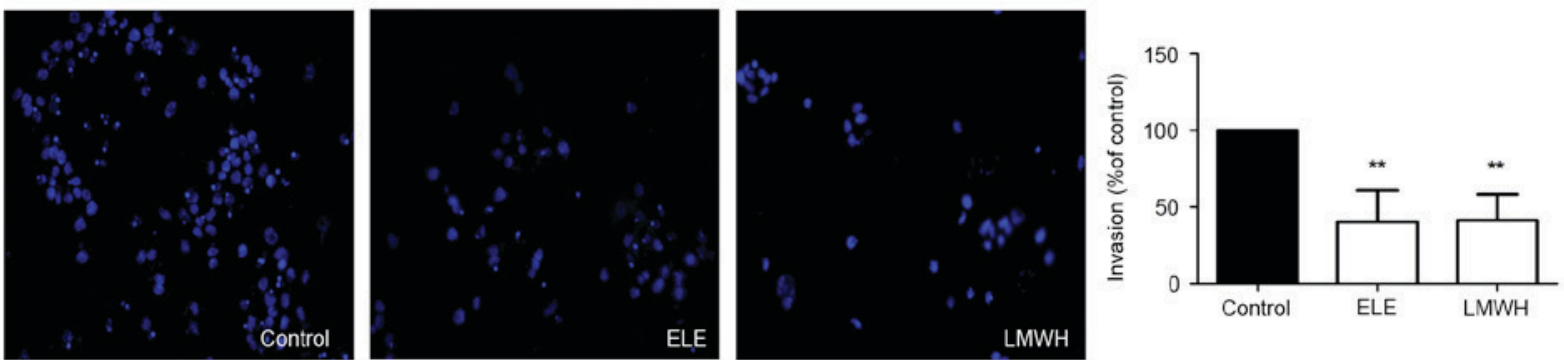

Invasion

Figure 3. ELE decreases the migratory and invasive ability of 4T1 cells. (A) xCELLigence DP system recorded and collected 4T1 cell migration data every $30 \mathrm{~min}$ for $24 \mathrm{~h}$ following ELE or LMWH treatment of cells. After 18 and $24 \mathrm{~h}$, the differences in cell indices between the drug-treated (ELE and LMWH) and control groups were significant. Data are presented as the mean \pm standard deviation of three wells. A representative time course of cell indices is shown $\left({ }^{* *} \mathrm{P}<0.01\right.$, vs. control). (B and $\mathrm{C}$ ) Cells migrated or invaded to the basal side of the membrane, were stained and images were captured using a Leica fluorescence microscope under x200 magnification. ELE and LMWH reduced the migration and invasion of 4T1 cells. Results are presented in graphs as the percentage of the control $\left({ }^{* *} \mathrm{P}<0.01\right.$, vs. control). ELE, elemene; LMWH, low-molecular weight heparin.

and control groups at 18 and $24 \mathrm{~h}$ were significant $(\mathrm{P}<0.01$; Fig. 3A). The results of the Transwell assay also demonstrated that the 4T1 cells exhibited reduced migration and invasion in response to ELE and LMWH treatment ( $\mathrm{P}<0.01$; Fig. 3B and $\mathrm{C})$. The above data indicated that ELE inhibited the migratory and invasive capacity of the 4T1 cells.

ELE downregulates the expression of heparanase, and suppresses the phosphorylation of ERK and AKT. In order to analyze the mechanisms underlying the effect of ELE on 4T1 cell migration and invasion, the present study examined the expression of heparanase and associated proteins in ELE-treated cells. ELE treatment resulted in significant decreases in the expression of heparanase, FGF-2 and VEGF $(\mathrm{P}<0.05$; Fig. 4B and $\mathrm{C})$. LMWH treatment had a similar effect on the expression of heparanase $(\mathrm{P}<0.01)$, however, only marginal decreases were observed in the expression levels of FGF-2 and VEGF (Fig. 4B and C). As is already known, the overexpression of heparanase or released growth factors from ECM enhance the activation of ERK and AKT. In the present study, the phosphorylation levels of ERK and AKT were suppressed following drug treatment $(\mathrm{P}<0.01$; Fig. 4D).

\section{Discussion}

In the present study, ELE was demonstrated to induce significant cell toxicity in human and murine breast cancer cells in a dose-dependent manner. The 4T1 cells were selected for further investigation due to their higher sensitivity to ELE. These results are consistent with previous findings that ELE has cytotoxic effects on several types of solid tumor cell $(15,23,24)$. Furthermore, the present study demonstrated the inhibitory effect of ELE on cell invasion and migration using three cellular models of metastasis. ELE inhibited the migratory and invasive ability of 4T1 cells, and the inhibitory rates were comparable to those of LMWH, which is a potential inhibitor of cancer metastasis $(25,26)$.

During cancer metastasis, ECM degradation is an important process. The overexpression of heparanase in cancer cells, involved in the degradation of ECM, has been considered a 
A
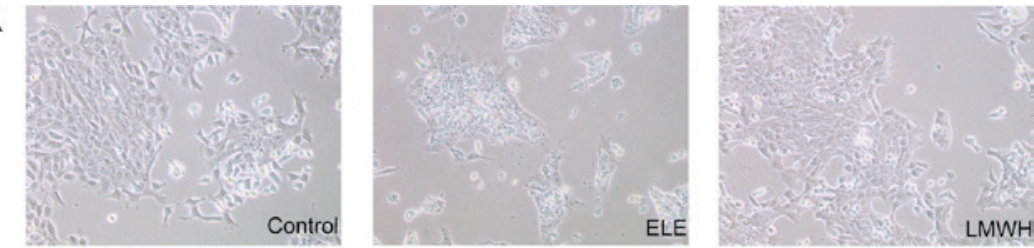

B
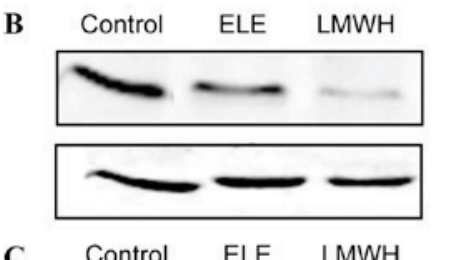

C
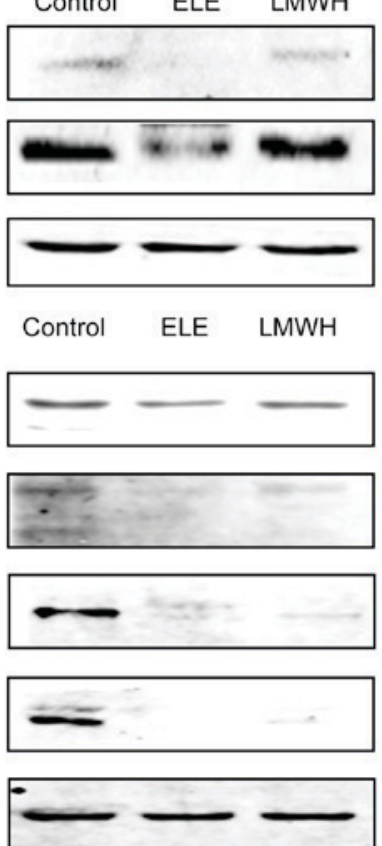

Heparanase

$\beta$-actin

FGF-2

VEGF

$\beta$-actin

ERK

p-ERK

AKT

E
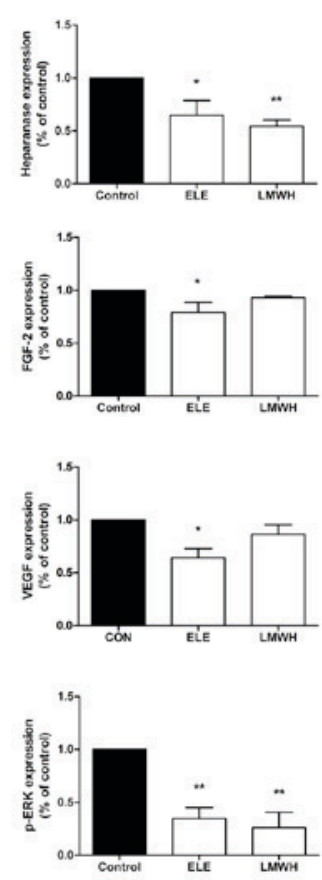

p-AKT

$\beta$-actin

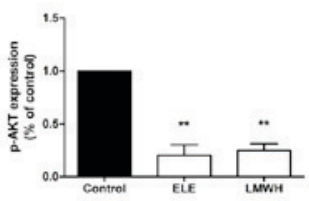

Figure 4. ELE reduces the expression of heparanase, and suppresses the phosphorylation of ERK and AKT. (A) 4T1 cells were cultured in medium containing ELE and LMWH. Photomicrographs were captured under x100 magnification. The expression levels of (B) heparanase, (C) FGF-2, VEGF, (D) ERK/p-ERK and AKT/p-AKT were analyzed using western blot analysis. The relative abundance of each band to $\beta$-actin was quantified and the control level was set to 1 . (E) Data representation of the expression levels. ${ }^{* *} \mathrm{P}<0.01$ and ${ }^{*} \mathrm{P}<0.05$, compared with the control. ELE, elemene; LMWH, low-molecular weight heparin; FGF-2, fibroblast growth factor-2; VEGF, vascular endothelial growth factor; ERK, extracellular signal-regulated kinase; p-, phosphorylated.

promising target for anticancer metastatic therapy. The inhibition of the expression of hepranase can effectively reduce the potential of cancer metastasis $(11,27)$. Therefore, it is necessary to identify drugs with antiheparanase effects. Previous studies have shown that ELE decreases breast cancer cell invasion and migration through upregulating the expression of E-cadherin, downregulating the expression of MMPs or inhibiting EMT by suppressing nuclear transcription factors $(16,18,28)$. By contrast, the results of the present study demonstrated that ELE downregulated the expression of heparanase, reduced levels of growth factors, and inactivated the phosphorylation of ERK and AKT, which is associated with cancer growth and metastasis. Various antiheparanase agents, including heparin, PI-88, PG545, M402 and SST0001, have been developed and shown to inhibit cancer metastasis (7,29-33). Consistent with the results of the present study, these previous studies revealed that the downregulation of heparanase and growth factors decreased the phosphorylation of ERK and AKT. Therefore, the findings of the present study suggested that the inhibition of heparanase may contribute to the response of ELE in the regulation of cell invasion and migration.

In conclusion, the results of the present study confirmed the antiproliferative and antimetastatic effects of ELE in vitro. Furthermore, the inhibitory effects of ELE were, at least partly, associated with downregulation of the expression of heparanase. Considering the aforementioned observations, ELE may be a promising agent for the antitumor and antimetastatic treatment of breast cancer.

\section{Acknowledgements}

The present study was supported by the National Natural Science Foundation of China (grant nos. 81373815 and 81202840), the Specialized Research Fund for the Doctoral Program of Higher Education of China (grant no. 20131107110014), the Beijing Natural Science Foundation of China (grant no. 7162084) and the Beijing Municipal Science and Technology Project (grant no. D161100005116005). 


\section{References}

1. Torre LA, Bray F, Siegel RL, Ferlay J, Lortet-Tieulent J and Jemal A: Global cancer statistics, 2012. CA Cancer J Clin 65: 87-108, 2015

2. Shi XJ, Au WW, Wu KS, Chen LX and Lin K: Mortality characteristics and prediction of female breast cancer in China from 1991 to 2011. Asian Pac J Cancer Prev 15: 2785-2791, 2014.

3. Guan X: Cancer metastases: Challenges and opportunities. Acta Pharm Sin B 5: 402-418, 2015.

4. Brown GT and Murray GI: Current mechanistic insights into the roles of matrix metalloproteinases in tumour invasion and metastasis. J Pathol 237: 273-281, 2015.

5. Vlodavsky I, Friedmann Y, Elkin M, Aingorn H, Atzmon R, Ishai-Michaeli R, Bitan M, Pappo O, Peretz T, Michal I, et al: Mammalian heparanase: Gene cloning, expression and function in tumor progression and metastasis. Nat Med 5: 793-802, 1999.

6. Maxhimer JB, Quiros RM, Stewart R, Dowlatshahi K Gattuso P, Fan M, Prinz RA and Xu X: Heparanase-1 expression is associated with the metastatic potential of breast cancer. Surgery 132: 326-333, 2002.

7. Li JP: Heparin, heparan sulfate and heparanase in cancer: Remedy for metastasis? Anticancer Agents Med Chem 8: 64-76, 2008

8. Wu BW, Li DF, Ke ZF, Ma D, Li YJ, Gang D, Zheng ZG, Zhang KJ and Zhang YH: Expression characteristics of heparanase in colon carcinoma and its close relationship with cyclooxygenase- 2 and angiogenesis. Hepatogastroenterology 57: 1510-1514, 2010.

9. Fernandes dos Santos TC, Gomes AM, Paschoal ME, Stelling MP, Rumjanek VM, Junior Ado R, Valiante PM, Madi K, Pereira de Souza HS, Pavão MS and Castelo-Branco MT: Heparanase expression and localization in different types of human lung cancer. Biochim Biophys Acta 1840: 2599-2608, 2014.

10. Davidson B, Shafat I, Risberg B, Ilan N, Trope' CG, Vlodavsky I and Reich R: Heparanase expression correlates with poor survival in metastatic ovarian carcinoma. Gynecol Oncol 104: 311-319, 2007.

11. Zhang L, Sullivan PS, Goodman JC, Gunaratne PH and Marchetti D: MicroRNA-1258 suppresses breast cancer brain metastasis by targeting heparanase. Cancer Res 71: 645-654, 2011.

12. Vlodavsky I, Fuks Z, Ishai-Michaeli R, Bashkin P, Levi E, Korner G, Bar-Shavit R and Klagsbrun M: Extracellular matrix-resident basic fibroblast growth factor: Implication for the control of angiogenesis. J Cell Biochem 45: 167-176, 1991.

13. Vlodavsky I, Goldshmidt O, Zcharia E, Atzmon R, Rangini-Guatta Z, Elkin M, Peretz T and Friedmann Y: Mammalian heparanase: Involvement in cancer metastasis, angiogenesis and normal development. Semin Cancer Biol 12: 121-129, 2002

14. Gingis-Velitski S, Zetser A, Flugelman MY, Vlodavsky I and Ilan N: Heparanase induces endothelial cell migration via protein kinase B/Akt activation. J Biol Chem 279: 23536-23541, 2004.

15. Lu JJ, Dang YY, Huang M, Xu WS, Chen XP and Wang YT: Anti-cancer properties of terpenoids isolated from Rhizoma Curcumae-a review. J Ethnopharmacol 143: 406-411, 2012.

16. Zhang X, Li Y, Zhang Y, Song J, Wang Q, Zheng L and Liu D: Beta-elemene blocks epithelial-mesenchymal transition in human breast cancer cell line MCF-7 through Smad3-mediated down-regulation of nuclear transcription factors. PLoS One 8: e58719, 2013

17. Yan B, Zhou Y, Feng S, Lv C, Xiu L, Zhang Y, Shi J, Li Y, Wei $\mathrm{P}$ and $\mathrm{Qin} \mathrm{Z}$ : $\beta$-Elemene-attenuated tumor angiogenesis by targeting notch-1 in gastric cancer stem-like cells. Evid Based Complement Alternat Med 2013: 268468, 2013.

18. Shi H, Liu L, Liu L, Geng J, Zhou Y and Chen L: $\beta$-Elemene inhibits the metastasis of B16F10 melanoma cells by downregulation of the expression of uPA, uPAR, MMP-2, and MMP-9. Melanoma Res 24: 99-107, 2014.
19. Teoh ML, Fitzgerald MP, Oberley LW and Domann FE: Overexpression of extracellular superoxide dismutase attenuates heparanase expression and inhibits breast carcinoma cell growth and invasion. Cancer Res 69: 6355-6363, 2009.

20. Gong F, Jemth P, Escobar Galvis ML, Vlodavsky I, Horner A, Lindahl U and Li JP: Processing of macromolecular heparin by heparanase. J Biol Chem 278: 35152-35158, 2003.

21. Szulcek R, Bogaard HJ and van Nieuw Amerongen GP: Electric cell-substrate impedance sensing for the quantification of endothelial proliferation, barrier function, and motility. J Vis Exp, 2014 doi: 10.3791/51300.

22. Mandel K, Seidl D, Rades D, Lehnert H, Gieseler F, Hass R and Ungefroren $\mathrm{H}$ : Characterization of spontaneous and TGF- $\beta$-induced cell motility of primary human normal and neoplastic mammary cells in vitro using novel real-time technology. PLoS One 8: e56591, 2013.

23. Li QQ, Wang G, Huang F, Banda M and Reed E: Antineoplastic effect of beta-elemene on prostate cancer cells and other types of solid tumour cells. J Pharm Pharmacol 62: 1018-1027, 2010.

24. Chen W, Lu Y, Wu J, Gao M, Wang A and Xu B: Beta-elemene inhibits melanoma growth and metastasis via suppressing vascular endothelial growth factor-mediated angiogenesis. Cancer Chemother Pharmacol 67: 799-808, 2011.

25. Ettelaie C, Fountain D, Collier ME, Beeby E, Xiao YP and Maraveyas A: Low molecular weight heparin suppresses tissue factor-mediated cancer cell invasion and migration in vitro. Exp Ther Med 2: 363-367, 2011.

26. Zhong GX, Gong Y, Yu CJ, Wu SF, Ma QP, Wang Y, Ren J, Zhang XC, Yang WH and Zhu W: Significantly inhibitory effects of low molecular weight heparin (Fraxiparine) on the motility of lung cancer cells and its related mechanism. Tumour Biol 36 : 4689-4697, 2015.

27. Liu H, Chen X, Gao W and Jiang G: The expression of heparanase and microRNA-1258 in human non-small cell lung cancer. Tumour Biol 33: 1327-1334, 2012.

28. Zhang X, Zhang Y and Li Y: $\beta$-elemene decreases cell invasion by upregulating E-cadherin expression in MCF-7 human breast cancer cells. Oncol Rep 30: 745-750, 2013.

29. Joyce JA, Freeman C, Meyer-Morse N, Parish CR and Hanahan D: A functional heparan sulfate mimetic implicates both heparanase and heparan sulfate in tumor angiogenesis and invasion in a mouse model of multistage cancer. Oncogene 24 : 4037-4051, 2005.

30. Zhou H, Roy S, Cochran E, Zouaoui R, Chu CL, Duffner J, Zhao G, Smith S, Galcheva-Gargova Z, Karlgren J, et al: M402, a novel heparan sulfate mimetic, targets multiple pathways implicated in tumor progression and metastasis. PLoS One 6: e21106, 2011.

31. Winterhoff B, Freyer L, Hammond E, Giri S, Mondal S, Roy D, Teoman A, Mullany SA, Hoffmann R, von Bismarck A, et al: PG545 enhances anti-cancer activity of chemotherapy in ovarian models and increases surrogate biomarkers such as VEGF in preclinical and clinical plasma samples. Eur J Cancer 51: 879-892, 2015

32. Hammond E, Brandt R and Dredge K: PG545, a heparan sulfate mimetic, reduces heparanase expression in vivo, blocks spontaneous metastases and enhances overall survival in the 4T1 breast carcinoma model. PLoS One 7: e52175, 2012.

33. Ritchie JP, Ramani VC, Ren Y, Naggi A, Torri G, Casu B, Penco S, Pisano C, Carminati P, Tortoreto M, et al: SST0001, a chemically modified heparin, inhibits myeloma growth and angiogenesis via disruption of the heparanase/syndecan-1 axis. Clin Cancer Res 17: 1382-1393, 2011. 